
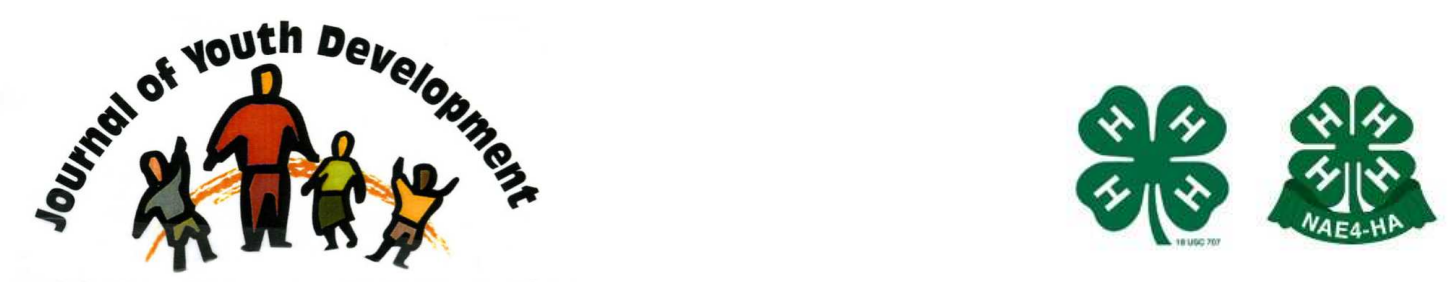

Bridging Research \& Practice

\title{
The 4-H Health Rocks! Program in Florida: Outcomes on Youth Tobacco, Alcohol, and Other Substance Abuse Prevention
}

\author{
Muthusami Kumaran \\ University of Florida \\ Gainesville, FL \\ kumaran@ufl.edu \\ Kate Fogarty \\ University of Florida \\ Gainesville, FL \\ kfogarty@ufl.edu
Amanda Terminello
University of Florida
Gainesville, FL \\ aterminello@gmail.com \\ Whitney M. Fung \\ Polk County Extension \\ University of Florida \\ Bartow, FL \\ whitneymfung@ufl.edu
}




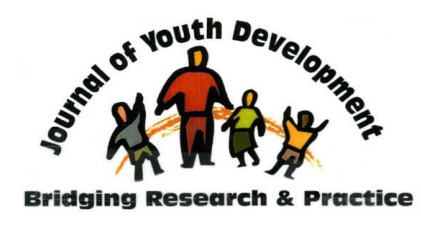

Volume 9, Number 2, Summer 2014

\section{JOURNAL OF YOUTH DEVELOPMENT \\ bridging research and practice}

\title{
The 4-H Health Rocks! Program in Florida: Outcomes on Youth Tobacco, Alcohol, and Other Substance Abuse Prevention
}

\author{
Muthusami Kumaran, Kate Fogarty, Amanda Terminello and Whitney M. Fung \\ University of Florida
}

\begin{abstract}
Youth tobacco, alcohol, and other substance abuse is a serious concern in the State of Florida, as well as across the nation. 4-H Health Rocks! is a positive youth development prevention program that utilizes experiential learning methods and youth-adult partnerships. The program and supporting curriculum were designed to foster personal and social skills to better equip adolescents to overcome pressures to participate in substance use. The purpose of this article is to describe the implementation of Health Rocks! in Florida and program evaluation including its impact on participants' drug knowledge, drug beliefs and attitudes, and drug resistance skills. Program evaluation indicates that 4-H Health Rocks! resulted in statistically significant improvement in each of these categories for hundreds of youth reached in 2009-2012. The importance of program components in preventing and influencing adolescent substance abuse are discussed.
\end{abstract}

\section{Introduction}

Across the United States and Florida, youth face a variety of emergent healthy living issues including tobacco, alcohol, and other drug use. According to the Florida Youth Substance Abuse Survey (FYSAS) (2012), covering selected middle and high schools in 66 out of 67 Florida counties, thirty eight percent (38\%) of high-risk (higher than average risk factor scores) sixth through eighth grade students reported laws and norms favorable to drug use in their communities and $40 \%$ believed that drugs were largely available in their communities. Nineteen percent (19\%) of the high-risk middle school students reported that their parents had favorable attitudes toward alcohol and other drug use. In addition, $28.9 \%$ of Florida middle school students reported having used alcohol in their lifetime, of which $12.3 \%$ reported having consumed alcohol in the past 30 days and $4.7 \%$ reported having consumed five or more alcoholic drinks (binge drinking) in the past two weeks. Furthermore, $8.3 \%$ of Florida middle 
school students reported ever using marijuana, of which $4.2 \%$ reported using marijuana or hashish in the last 30 days. Among Florida high school students, 14.5\% reported that they had started smoking cigarettes at age thirteen or younger.

According to the Florida Youth Substance Abuse Survey (FYSAS) (2012), Florida's middle school students surpassed high school students in lifetime inhalant use (9.9\% versus $6.4 \%)$, with $3.8 \%$ of middle school students having used inhalants in the past 30 days. Middle school students were also more likely to think they had a "good chance of being seen as cool" if they smoked cigarettes as compared to high school students (5.7\% versus $5.2 \%)$. However, a greater proportion of high school than middle school students thought they had a "good chance of being seen as cool" for drinking alcohol regularly (14.3\% versus $7.6 \%)$ and smoking marijuana (18.4\% versus $10.8 \%)$.

In response to communities' needs to address adolescent drug use and results of the Florida Youth Substance Abuse Survey, the Cooperative Extension System in Florida implemented several statewide efforts to address these needs. In 2011, the Extension Community Input Survey was conducted among Extension professionals and stakeholders in Florida in order to pinpoint priority educational needs in their communities. Among the 4,294 respondents, top priorities in meeting the youth development needs of clientele lined up with several of the 4-H Health Rocks! program's educational goals, namely: teaching youth responsibility and positive alternatives to substance abuse $(72.1 \%)$ and helping youth develop healthy lifestyles (71.3\%), including exercise, smoking cessation, and drug and alcohol abuse prevention (University of Florida Institute of Food and Agricultural Sciences Extension, 2011).

Furthermore, Florida 4-H teens identified drinking and drug use as the most risky behavior faced by their peers according to a forum activity, 4-H Engaging Youth Serving Communities. The forum was conducted in December of 2010 with Florida 4-H state council officers and executive board members ages fourteen to eighteen from across the state of Florida (Davis, Zimmerman, Padgett, Pace, \& Avant, 2010). Participating teens also identified peer pressure and gang involvement as prevalent risky behaviors. In terms of addressing these risky behaviors, the teens believed that the best solutions included finding healthy or positive alternative activities; setting a positive example; being the voice of reason to their generation; and being a role model or encouraging positive behaviors in younger youth.

\section{Positive Youth Development}

The positive youth development approach focuses on the positive assets of an individual as a means to potentially prevent negative adolescent outcomes, such as delinquent behaviors (Schwartz, et al., 2010). This approach shifts focus from pathology and negative adolescent outcomes in order to build on and increase strengths of the individual. Positive youth development interventions emphasize and value the potential of adolescents and provide them with a sense of belonging and connectedness. These interventions also tend to allow for opportunities for meaningful engagement and community service and participation (Cheon, 2008). Many positive youth development interventions focus on: promoting bonding; fostering resilience; promoting social, emotional, cognitive, behavioral, and moral competence; fostering self-determination; fostering spirituality; fostering self-efficacy; fostering clear and positive identity; fostering belief in the future; providing recognition for positive behavior and opportunities for prosocial involvement; and fostering prosocial norms (Catalano, Berglund, Ryan, Lonczak, \& Hawkins, 2002). Research has shown support for positive youth development interventions as a successful and promising approach to adolescent prevention efforts (Cheon, 2008; Catalano, et al., 2002; Schwartz, et al., 2010). 


\section{Characteristics of Successful Positive Youth Development Interventions}

Previous reviews have shown that there are several characteristics of successful positive youth development interventions aimed at adolescent substance use prevention that emerge. According to a study by Cheon (2008), interventions that have shown to be effective tend to: have clearly articulated goals; target at-risk youth; be developmentally appropriate; incorporate the school or community; have structured alternative activities; incorporate peer leadership and mentoring; and include family involvement. According to a study conducted by Catalano, et al. (2002), themes of successful programs included methods to: strengthen social, emotional, behavioral, cognitive, and moral competencies; increase self-efficacy; incorporate messages from family and community about standards for positive and healthy behaviors; promote healthy bonding with adults and peers; and expand opportunities and recognition for youth to engage in positive activities. According to a review conducted by Botvin and Griffin (2007), effective programs tend to: be guided by a comprehensive theoretical framework; provide developmentally appropriate information; incorporate material to recognize and resist pressures to engage in drug use; incorporate personal and social skills training; provide accurate health information regarding rates of substance use in order to reduce the perception that it is normative; be delivered using interactive and participative methods; and be culturally sensitive. In addition, Glynn (1989) reported that an effective school-based smoking prevention program included: delivering approximately ten hours of educational programming; involving sixth through ninth graders prior to their involvement in risky behaviors; utilizing teacher training and experiential learning activities in teacher training as well as experiential curriculum for student engagement; incorporating potential parental support; easy implementation; and the use of youth-adult partnership or a teacher-led, peer-assisted approach to deliver the program. More recent evidence of effective smoking cessation programs for youth pointed to the overlap among facets of healthy lifestyles in which combining exercise with smoking cessation proved more effective than smoking cessation alone (Horn, et al., 2013).

\section{The Florida Health Rocks! Program}

Education in healthy living for youth and families is one of several national 4-H "mission mandates." In 2009, the University of Florida was one of ten land-grant universities to receive grants from the National 4-H Council to support their Health Rocks! program. The main goal for each state grantee was to reach between 1,000 and 10,000 youth with at least ten hours of Health Rocks! programming guided by the intermediate, middle school Health Rocks! curriculum. Grantees were also expected to plan for a sustainable program that would be viable beyond the three-year funding period ending in 2012 and engage in an extensive, systematic evaluation of outcomes experienced by youth program participants in Health Rocks!

The Florida Health Rocks! program is a collaboration between the National 4-H Council, the University of Florida, and cooperative extension professionals. This program design allows for a similar, though not uniform, structure to be shared by various program partners and locations. In essence, the National 4-H Council designated responsibilities and requirements for the nationally-recognized curriculum, such as a minimum requirement of 10 or more hours of education from a variety of lessons in the intermediate curriculum. National 4-H Council also provided structural support and resources to other key program partners such as teachers and Extension agents, including informational webinars. The Florida Health Rocks! team at the University of Florida communicated regularly with the National 4-H Council and local county extension professionals in order to coordinate program implementation, resource distribution, program evaluation, and other supportive assistance to ensure effective and efficient program 
delivery. 4-H Health Rocks! program leaders in each state also provided "train the trainer" sessions statewide to county extension professionals and volunteers in order to develop, implement, evaluate, and sustain program education at various sites. Local extension professionals, mainly 4-H and Family and Consumer Science extension agents, maintained responsibility for the delivery of Health Rocks! programming in their respective counties, including the recruitment, education, and sustainability of program volunteers and staff.

One of the core tenets of the Health Rocks! program is the use of youth-adult partnerships in which teens and adults collaborate in order to teach lessons from the intermediate Health Rocks! curriculum to the youth participants. Utilizing youth-adult partnerships encourages healthy bonds between youth and adults, provides opportunities for youth participation and leadership, and communicates clear messages about acceptable behavioral standards (Catalano, et al., 2002).

Another core tenet of the Health Rocks! program is the extensive use of Health Rocks! curricula and lesson plans, which were designed to reflect recent social science research such as reports from Centers for Disease Control and Prevention (CDC) Youth Risk Behavior Survey data reports and Monitoring the Future Study. How the curriculum fulfills national health education standards is covered and the Florida 4-H Health Rocks! program coordinators matched lesson plans with "Sunshine State" Health Education Standards from $6^{\text {th }}$ through $12^{\text {th }}$ grades to increase the programs' appeal to middle school health teachers. The curricula series consists of the Health Rocks! Beginning Level, aimed at youth aged eight to twelve and Health Rocks! Intermediate Level, aimed at youth aged twelve to fifteen. Currently, the main emphasis of the Florida 4-H Health Rocks! program is outreach using the intermediate level curriculum with middle school students. Program evaluation for Health Rocks! was reviewed by the University of Florida Institutional Review Board.

The Health Rocks! curricula utilizes the experiential learning method which allows youth to learn through hands-on participation, reflection, and application to real-life situations (Kolb, 1984). As mentioned, the intermediate curriculum meets National and Florida Health Education Standards; provides accurate and up-to-date research-based health information regarding consequences of youth tobacco, alcohol, and drug usage; and is designed to foster building of assets needed for successful youth development through life skill acquisition. Building life skills promotes youth social, emotional, and behavioral competencies, with self-efficacy in these areas as a byproduct. Major life skills covered in the intermediate curriculum include: decision-making, critical thinking, communication, managing feelings, stress management, goal setting, and serving the community, as seen in the Iowa Life Skills Model (Iowa State University Extension and Outreach, n.d.). This curriculum also covers key areas linked to teen drug use such as building refusal skills and understanding media influences, as well as community outreach by youth in partnership with adults, to prevent drug abuse. The objectives and skills highlighted in the Health Rocks! curricula are characteristic of successful and effective positive youth development approaches aimed at adolescent substance use prevention (Botvin, \& Griffin, 2007; Cheon, 2008; Catalano, et al., 2002; Schwartz, et al., 2010).

Since the program began in 2009, the University of Florida Health Rocks! program has reached youth in twelve of Florida's sixty-seven counties, including Broward County, home to the nation's sixth largest public school district. (To note: Health Rocks! has been most prevalent in 4-H in the classroom and afterschool programs.) Through the support of county extension professionals, key program staff and volunteers, and local public school systems, the program 
soon grew and was implemented beyond 4-H clubs into afterschool programs, school enrichment programs (4-H in the classroom), and certain county public school systems. Purpose of this Paper

The aim of this paper is to describe the evaluation results of the Florida Health Rocks! program and link those findings to program implementation (improvement) and sustainability. We will start by describing the program impact on youth knowledge, beliefs, attitudes, and behavioral resistance skills regarding youth tobacco, alcohol, and drug use.

As part of this evaluation process, youth participants completed retrospective pre- and posttest evaluation surveys that covered general demographic information and measured the progress they believe they have made as a result of participating in the program. Likert scaletype questions were broken down into three major variable areas, determined by factor analysis: drug knowledge, drug beliefs and attitudes, and behavioral skills to handle and resist drugs. The surveys allowed analysis of the impact of the program and provided valuable information to the Florida Health Rocks! team and other key program stakeholders. The findings have been and will continue to be used in order to improve implementation and highlight program success.

\section{Methodology}

\section{Sample}

The sample populations for this evaluation study are the youth who participated in the Florida Health Rocks! program. These youth were recruited by local county extension professionals from diverse settings ranging from afterschool programs, 4-H clubs, and public school health classes and range from ten to fifteen years old. Youth came from 7 Florida counties of which the majority of youth $(52.5 \%, \mathrm{~N}=436)$ resided in urban areas, followed by suburban residences $(29.5 \% \mathrm{~N}=245)$. Only $10.8 \%(\mathrm{~N}=90)$ of youth reported living in rural areas. $11.7 \%(\mathrm{~N}=48)$ reported being Hispanic/Latino and African-Americans $(34.9 \%, \mathrm{~N}=332)$ outnumbered Caucasians slightly $(34.5 \%, \mathrm{~N}=328)$. Eleven youth $(1.3 \%)$ reported being of Native American descent, $13(1.5 \%)$ reported being Asian, and 74 (8.5\%) reported as multi-racial. Male participants who completed surveys ( $\mathrm{N}=453$ or $48.5 \%)$ outnumbered females slightly $(\mathrm{N}=441$ or $47.2 \%)$ and the mode age of participants was 13 years $(\mathrm{N}=198$ or $22.9 \%)$ with an average age of outreach (range $=5$ to 19 years of age) of 11.59. The mode grade of participants was eighth ( $\mathrm{N}=231$ or $25.5 \%$ of participants who completed evaluations). The majority of participants ( $\mathrm{N}=535$ or $62.4 \%$ ) reported receiving 8-10 hours of Health Rocks! education with a minority receiving 7 hours or less $(\mathrm{N}=47$ or $5.5 \%)$. Others $(\mathrm{N}=275$ or $32.1 \%)$ reported receiving 10 or more hours of Health Rocks! education. Participants on average engaged in and completed 9.01 activities from the Health Rocks! curriculum, demonstrating that the majority of participants were exposed to the diverse aspects of the curriculum (e.g., goal setting, decisionmaking, handling peer pressure, drug knowledge, community awareness).

\section{Data Collection}

The Florida Health Rocks! team conducted over twenty-five trainings with volunteers and staff on program implementation and appropriate evaluation methods and protocol, including informed consent procedures and confidentiality guidelines. (Institutional Review Board approval was received on a yearly basis to evaluate the program). Program instructors distributed evaluation questionnaires to participants at the conclusion of program delivery, after youth participated in 10 hours of programming, and provided the completed surveys to the Florida Health Rocks! team to standardize. 


\section{Data Analysis}

The National 4-H Council provided data analysis for each participating state in the Health Rocks! program. The Florida Health Rocks! team conducted statistical analysis on the demographic data and pre- and post- test responses (from the retrospective pre- and post- test survey) using SPSS Version 20.0. Next we will focus on findings collected by the Florida Health Rocks! team.

\section{Program Outcomes and Results}

Chart 1 shows a summary of evaluation results of participants who completed the Health Rocks! evaluation questionnaire between 2009 and 2012. A statistically significant change in mean scores are found in all categories, indicating that Health Rocks! program improves participating youth's drug knowledge, anti-drug beliefs and attitudes, and behavioral skills to resist using drugs.

\section{Chart 1}

Evaluation Results of Health Rocks! Participants 2009-2012

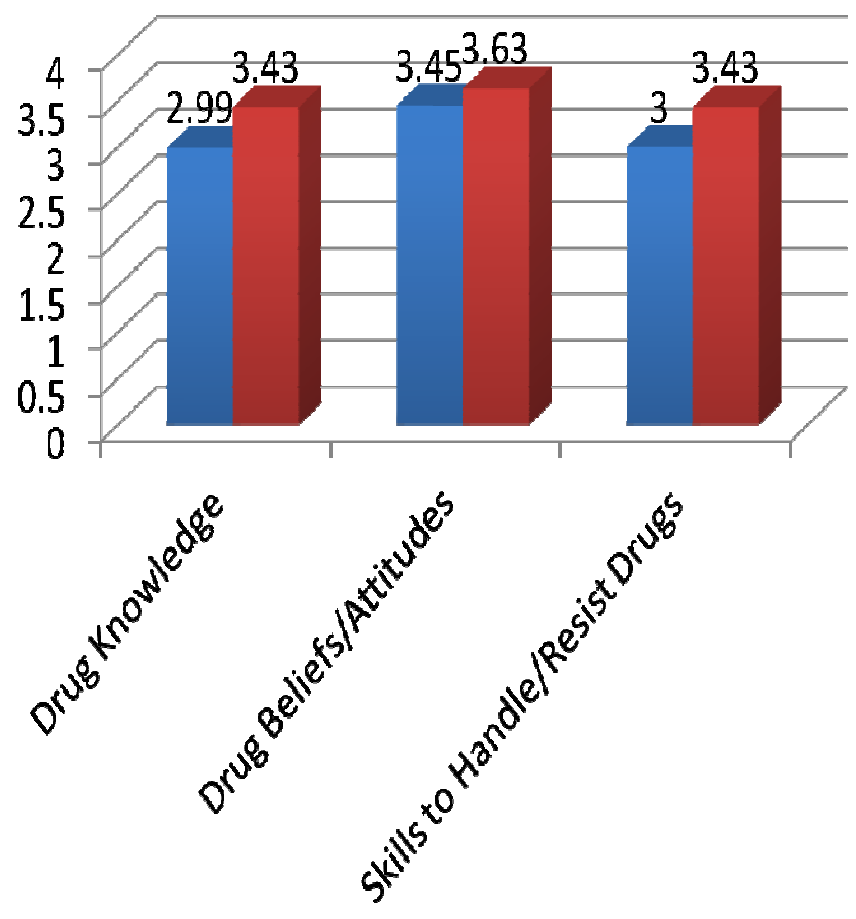

Before Receiving Health Rocks Training After Receiving Health Rocks Training

Note: *All differences significant at the $\mathrm{p}<.001$ level $* *$ Final $\mathrm{N}=528-703$ (Complete Data on Each Indicator) $* * *$ Scale 1 (Strongly Disagree) - 4 (Strongly Agree)

Statistical analysis included running paired sample tests on SPSS in which the perceived mean scores before the education were compared with the mean scores after the program. These results are shown in Table 1. 
Table 1

Changes in Knowledge, Attitudes and Skills as a Result of Participating in Health Rocks!

\begin{tabular}{lcccccc} 
& \multicolumn{2}{c}{ Before Program } & \multicolumn{2}{c}{ After Program } & & \\
\cline { 2 - 4 } Measure & $M$ & $S D$ & $M$ & $S D$ & $t(1,705)$ & $p$ \\
\hline Drug Knowledge & 2.99 & .79 & 3.43 & .59 & -16.45 & $<.001$ \\
Drug Beliefs/Attitudes & 3.45 & .59 & 3.63 & .50 & -8.57 & $<.001$ \\
Behavioral Skills & 3.00 & .03 & 3.43 & .02 & -15.65 & $<.001$ \\
\hline
\end{tabular}

Note: The Health Rocks! evaluation survey was in retrospective pre-test/post-test format

\section{Drug Knowledge}

Drug knowledge items included: "Once you start using drugs, it is hard to stop;" "People who use drugs sometimes see or hear things that are not really there;" and "People who smoke can die from lung cancer." Of the total 952 evaluations, there were 705, with some mean substitution items, for which there was complete data on all 4 items for both pre- and post tests. On a scale of 1-Strongly Disagree to 4 - Strongly Agree, the average knowledge score shifted from 2.99 on pre-test to 3.43 on the post-test. Out of 705 responses, 491 reported positive knowledge change on the 4 items, whereas 196 reported no change across items. Positive change overall was statistically significant $(p<.001)$.

\section{Drug Beliefs/Attitudes}

Drug beliefs and attitudes items included "I need to think about how my choices will affect my future;" and "It is important for me to stay focused on learning at school." For 528 of the 952 surveys, there were complete data on all 3 items for both before and after ( 6 items total). The average attitude score shifted from 3.45 before to 3.63 after program participation on a scale of 1 - Strongly Disagree to 4 - Strongly Agree. Of the 598 respondents, 179 reported positive attitude change on the 3 items from before to after Health Rocks! program participation, whereas 349 reported no change to negative change. Positive change in attitudes overall was statistically significant $(p<.001)$.

\section{Decision Making/Behavioral skills to Handle and Resist Drugs}

Drug resistance skills items included: "I am able to say 'no' if others offered me drugs;" "When I feel stressed I am able to talk about it with people I trust;" and "If a friend wanted to try drugs, I can talk them out of it." For 702 of the 952 surveys, there were complete data on all 5 items for both pre- and post tests (10 items total). The average decision-making behavioral skills score changed from 3.00 to 3.43 between pre- and post-tests on a scale of 1 - Strongly Disagree to 4 - Strongly Agree. Of the 703 responses, 464 subjects reported positive change in behavioral decision making skills on the 5 items from before to after Health Rocks education, whereas 239 reported no change to negative change. Positive change in decision-making skills overall was statistically significant $(p<.001)$.

\section{Discussion}

In the hopes to prevent or reduce substance abuse among middle school youth, Florida 4-H Health Rocks! has provided a strong programmatic foundation for the implementation and evaluation to be replicated in other sites and states. Program evaluation results over the past few years indicate potential benefits to youth in decreasing the chances of youth tobacco, alcohol, and other drug use. The minimum requirement of 10 hours of education for program participants, although not complete in all implementation sites, may have contributed to gains in the three categories: drug knowledge, drug beliefs/attitudes, and decision-making/behavioral 
skills to handle or resist drugs. Health Rocks! program objectives are based on addressing these three categories throughout the lessons and the curriculum activities and pedagogy incorporates a variety of life skills for youth development to a broad number of topics such as health, self-awareness, social responsibility, or physical activity.

Drug knowledge varies from learning about the effects of stimulants and depressants to recognizing the types of drugs that exist and are used commonly among middle school youth. Program activities reinforce and elaborate on drug knowledge through participant discussion and hands-on activities. The curriculum also incorporates a fun, educational environment for youth to absorb the information. For example, a simple "Jeopardy" style game is included to test participants' knowledge about types of drugs and terms and an additional "Charades" style game is included to recognize the signs and symptoms of those drugs. The statistically significant changes found on drug knowledge, as a result of program participation is not surprising given curriculum content and the experiential design of activities. However, knowledge alone has not been shown to predict drug use behavior or intentions to use substances. Instead, information dissemination must be one element of a comprehensive approach that focuses on other factors, such as building drug refusal skills, correcting normative expectations regarding the prevalence of substance use, and increasing social and personal competence skills, in order to be effective in reducing substance use (Botvin, \& Griffin, 2007).

Specific skills to resist drugs such as "saying no" or "walking away" from a questionable or uncomfortable situation are also incorporated into the Health Rocks! curricula. Moreover, the lessons also incorporate broader skills such as decision making and its application to participants' daily lives. Stress management is a critical skill when children transition to adolescence and become susceptible to peer pressure, physical changes of puberty, challenging academics and more social interaction with school cliques as well as teachers. As indicated in the evaluation, participants reported a significant increase in their ability to make decisions as well as their skills to handle or resist drugs. Health Rocks! program activities provide a safe and comfortable setting for youth to discuss their problems and the situations they are going through that might relate to drugs. This opens the door of youth communication with adults and each other, such as teachers, parents, or older role models, which may further decrease their chances of substance abuse. Several studies have shown that teaching social resistance skills, such as skills to resist drugs and decision making, can reduce the proportion of adolescents regularly using alcohol, tobacco, and marijuana by up to $45 \%$. Some of these school-based programs have also been shown to have lasting benefits for up to three years after the conclusion of these programs (Botvin, \& Griffin, 2007).

Promoting consideration of participants' futures, combined with discussion on the consequences of drug use as they affect academic and personal success is another key theme in the Health Rocks! curricula. The statistically significant increase in positive future attitudes is likely to contribute to youth avoidance of alcohol and drug use and situations in which substances are available. They may be more likely to think about the choices they make which can significantly affect their future. Activities in the Health Rocks! program probe at youth's dreams for their future and encourage positive goal setting which would remind them of what they'd like to accomplish before engaging in risky behaviors. Fostering a belief in the future, selfdetermination, self-efficacy, and a clear and positive identity are key elements to positive youth development interventions targeting adolescent substance use prevention (Catalano, et al., 2002).

Lastly, changing children's and adolescents' views on drugs are an essential component to the program. The program does not use scare tactics; rather, it aims to inform participants of the 
situation and supply youth with positive developmental skills that would decrease their chances of engaging in substance abuse or other related behaviors. The lessons also incorporate topics that are relevant for children and adolescents based on the consequences of drugs relative to peer pressure and school situations. Because the program:

1) involves an interactive, hands-on educational curriculum;

2) is likely to be taught by youth and adults in partnership to younger youth; and

3) provides an open platform for discussion of participants to brainstorm and share their ideas and experiences.

Youth are more likely to understand drugs and substance use and further take a more responsible attitude toward such use. Program evaluations indicate that delivery using interactive methods to promote skill acquisition such as small group activities and role-playing scenarios, tend to be common in successful in achieving set goals for the prevention of adolescent substance use (Botvin, \& Griffin, 2007).

\section{Limitations}

In terms of the evaluation measures used, possible bias exists as it is a self-reported retrospective pre- and post- test measure. Participants may be more likely to misrepresent their drug knowledge, skills to resist drugs, and drug attitudes and beliefs at the end of the program as compared to before they participated. The recall of information from before the program was delivered may result in recall bias. It is also a possibility that less mature and younger youth may have had difficulty interpreting and responding to questionnaire items. In addition, the youth who completed the questionnaire may not be a representative sample of all of the youth who participate in the program as evaluation results were collected on anywhere between $50 \%$ to $95 \%$ of youth who participated in the program, depending on the site of implementation and data collection.

\section{Conclusion}

As Health Rocks! expands across the state of Florida in various forms of outreach such as afterschool programs, school enrichment or $4-\mathrm{H}$ in the classroom, and community club meetings, it is likely that tobacco, drug and alcohol use among youth, especially middle school students, will decline. In fact, overall Florida reported drug use by middle and high school students declined between 2010 and 2012 (FYSAS, 2012). However, the Health Rocks! program evaluation process does not currently possess capacity to link program impact with declines in middle school student drug use in a given county, as indicated by the Florida Youth Substance Abuse Survey (FYSAS). With increased support and collaboration with public school districts such as Health Rocks! receiving approval from county school board councils and curriculum coordinators, as well as local community organizations, citizens, volunteers, and higher education institutions, the outreach goals of the Florida 4-H Health Rocks! program can be achieved and can make a sustainable impact on communities throughout Florida.

Florida 4-H Health Rocks! is a valuable addition to the realm of promising practices in positive youth development and drug prevention programs. The foundation in positive youth development and the experiential design of the Health Rocks! curriculum allow for participants to potentially make positive changes in regards to drug knowledge, drug beliefs and attitudes, and decision-making skills. The core tenets and components of the program include:

1) developmentally appropriate;

2) targets at-risk youth; 
3) encourages youth-adult partnerships;

4) provides guidance toward healthy alternative activities;

5) builds personal and social competencies, such as refusal skills; and

6) provides accurate health information regarding the prevalence of adolescent substance use.

These features distinguish successful programs preventing, delaying, or reducing adolescent substance use (Cheon, 2008; Catalano, et al., 2002; Botvin, \& Griffin, 2007; Glynn, 1989). Adolescent health programs may benefit from understanding the current structure, implementation, and sustainability of the Health Rocks! program and learning from programmatic successes. This program serves as a model for community partnerships, including collaboration between cooperative extension, 4-H organizations, the public school system, and other community based organizations. The lessons learned from Health Rocks! and other similar programs can provide valuable insight into different approaches for targeting youth substance use issues.

\section{References}

Botvin, G.J., \& Griffin, KW. (2007). School-based programmes to prevent alcohol, tobacco, and other drug use. International Review of Psychiatry, 19(6), 607-615.doi:

10.1080/09540260701797753.

Catalano, R.F., Berglund, M.L., Ryan, J.A.M., Lonczak, H.S., \& Hawkins, J.D. (2002). Positive Youth Development in the United States: Research Findings on Evaluations of Positive Youth Development Programs. Prevention and Treatment, 5(15): 1-111. doi: 10.1037/15223736.5.1.515a.

Cheon, J.W. (2008). Best practices in community-based prevention for youth substance reduction: Towards strengths-based positive development policy. Journal of Community Psychology, 38(6), 761-779.

Davis, P., Zimmerman, W., Padgett, J., Pace, K., \& Avant, B. (2010, December). 4-H Engaging Youth Serving Communities. In J. Padgett, Chair and President, Second Executive Board Meeting of the Florida 4- $\mathrm{H}$ State Council. A youth forum symposium conducted at the second quarterly meeting of the Florida 4-H State Council, Altoona, Florida.

Florida Youth Substance Abuse Survey. (2012). Florida Department of Children \& Families. Retrieved September 4, 2013 from: http://www.dcf.state.fl.us/programs/samh/publications/fysas/10Survey/2010FYSASStateReportF inal.pdf.

Glynn, T.J. (1989). Essential elements of school-based smoking prevention programs. Journal of School Health, 59(5), 181-189.

Horn, K., Branstetter, S., Zhang, J., Jarret, T., Tompkins, N.O., Anesetti-Rothermel, et al. (2013). Understanding physical activity outcomes as a function of teen smoking cessation. Journal of Adolescent health, 53(1), 125-131. 
Kolb, D.A. (1984). Experiential learning: Experience as the source of learning and Development. New Jersey: Prentice-Hall.

Schwartz, S.J., Phelps, E., Lerner, J.V., Huang, S., Brown, C.H., Lewin-Bizan, S., Li, Y., \& Lerner, R.M. (2010). Promotion as prevention: Positive youth development as protective against tobacco, alcohol, illicit drug, and sex initiation. Applied Developmental Science, 14(4), 197-211. doi: 10.1080/10888691.2010.516186.

University of Florida Institute of Food and Agricultural Sciences Extension. (2011). [2011 Extension Community Input Survey]. Unpublished raw data.

(C) Copyright of Journal of Youth Development $~$ Bridging Research and Practice. Content may not be copied or emailed to multiple sites or posted to a listserv without copyright holder's express written permission. Contact Editor at: patricia.dawson@oregonstate.edu for details. However, users may print, download or email articles for individual use.

ISSN 2325-4009 (Print); ISSN 2325-4017 (Online) 